\title{
Factors Influencing the Formation of Single-Chain Polymeric Nano- particles Prepared via Ring-Opening Polymerization
}

\author{
Edgar H. H. Wong and Greg G. Qiao* \\ Department of Chemical and Biomolecular Engineering, The University of Melbourne, Parkville, Victoria 3010, Australia \\ KEYWORDS: single chain, self-folding, nanoparticles, ring-opening polymerization
}

\begin{abstract}
The development of single-chain polymeric nanoparticles (SCNP) has been of great scientific interest in recent years. Recently, we have developed a robust system to form SCNP at high polymer concentration (ca. $100 \mathrm{mg} \cdot \mathrm{mL}^{-1}$ ) via organocatalyzed ring-opening polymerization (ROP). In this approach, linear polymer precursors functionalized with pendent polymerizable caprolactone moieties undergo self-cross-linking in the presence of organo-catalyst and alcohol initiator. Following on from our previous communication, we report in here a more in-depth fundamental investigation to better understand our system. For this, we have synthesized various linear random copolymer precursors (i.e., poly(oligo(ethylene glycol) acrylate) (P1), polystyrene (P2), and poly(methyl acrylate) (P3)) by reversible addition fragmentation chain transfer (RAFT) polymerization, and their abilities to form SCNP at high polymer concentration were evaluated. It was found that only P1, which contain oligo(ethylene glycol) sidechains, was able to successfully form SCNP while the other linear precursors resulted in multi-chain aggregates, indicating the importance of side-chain brushes in aiding SCNP formation at high polymer concentration. Furthermore, we tested several multifunctional alcohol initiators (mono-, di-, and tetra-hydroxy) and found that the initiator structure has no effect on the SCNP formation process. In addition, we investigated the effect of initiator concentration and observed that the particle size can be reduced (from 7.6 to $6.6 \mathrm{~nm}$ ) when the initiator and linear precursor are in equimolar concentration. It is anticipated that the information derived from this study may lead to the development of new SCNP for targeted (bio)applications.
\end{abstract}

\section{INTRODUCTION}

Over the last few decades, the scientific community has witnessed a significant advancement in the synthesis of functional organic polymeric nanoparticles for a range of targeted applications, including controlled drug delivery, ${ }^{1,2,3}$ catalysis, ${ }^{4}$ membranes technologies, ${ }^{5}$ and as antibacterial agents. ${ }^{6,7}$ Controlled polymerization protocols such as $\mathrm{Cu}$-mediated radical polymerization, ${ }^{8-11}$ reversible addition fragmentation chain transfer (RAFT) polymerization ${ }^{12}$ and ring-opening polymerization (ROP) ${ }^{13,14}$ are now widely employed in the synthesis of such polymer nanoparticles as they enable for precise control over the molecular weight, functionality and topology of polymer constructs. For example, the synthesis of star polymers via an arm-first approach where linear macroinitiators are formed and chain-extended in the presence of cross-linkable monomers, forming discrete nanoparticles. ${ }^{15-18}$ Other strategies include the self-assembly of amphiphilic block copolymers to form micelles of various morphologies (e.g., sphere, cylinder, vesicles). ${ }^{19-23}$ Additionally, emulsion-based polymerizations have also been used in the preparation of polymer nanoparticles. $^{24}$

Another method of producing polymer nanoparticles that has been gaining popularity recently entails the self-collapse and intramolecular folding or cross-linking of single polymer chains. ${ }^{25-47}$ This class of nanoparticles, defined as single-chain polymeric nanoparticles (SCNP), mimics the self-folding action of natural biomacromolecules such as proteins and enzymes, and is generally in the size range of $<20 \mathrm{~nm}$. Whilst small nanoparticles have potentials for specific applications (e.g., drug delivery across the blood-brain-barrier ${ }^{48,49}$ ), accessibility to this size range has traditionally been difficult to achieve by other methodologies. Currently, a myriad of SCNP formation strategies have been reported that utilizes different linking chemistries to stabilize the particle structure, including dynamic covalent, covalent and noncovalent interactions. For instance, some of the earliest examples entailed the crosslinking of linear polymers functionalized with pendent vinyl groups via conventional free radical polymerization ${ }^{28}$ or alkene cross-metathesis. ${ }^{29}$ Other later examples include the photodimerization of 2-ureidopyrimidinone ${ }^{30}$ or anthracene, ${ }^{31}$ host-guest complexation between cucurbit $[n]$ uril and napthyl moieties, ${ }^{32}$ hydrogen bonding, ${ }^{33,34}$ (photo)click reactions, ${ }^{35,36,37}$ acylhydrazone formation between aldehyde and acylhydrazides $^{38}$ and hydrophobic physical interactions. ${ }^{39}$ Despite the availability of an expanding synthetic toolbox to generate SCNP, the majority of these systems need to be performed under (ultra-)dilute conditions to ensure single polymer chains preferentially undergo intra- over inter-polymer reactions.

We recently reported a new system to form SCNP via organo-catalyzed ROP where linear polymeric precursors functionalized with pendent polymerizable caprolactone groups are cross-linked intramolecularly in the presence of organocatalyst and alcohol initiator (Scheme 1a). ${ }^{45}$ This approach not only enables the efficient formation of SCNP under mild, metal-free conditions but also the formation of biocompatible and biodegradable polyester linkages that stabilize the nanoparticle. Interestingly, we observed the formation of well-defined SCNP even at high polymer concentration $\left(\sim 100 \mathrm{mg} \cdot \mathrm{mL}^{-1}\right)$, which was extremely rare, though we were not entirely certain 
of the reason behind this observation at that time. However, we suspected that the short oligo(ethylene glycol) (OEG) brushes in our model linear precursor (P1, Scheme 1b) may have aided the formation of SCNP at high polymer concentration. Two very recent reports, ${ }^{33,39}$ published around the same time as us, have also demonstrated the formation of SCNP at similarly high polymer concentrations even though the chemistries used to facilitate particle formation are distinguishable from one another. Mere coincidence or not, in both these systems, linear precursors containing OEG brushes were employed. However, no scientific evidence has been provided to explain the driving force behind the formation of these SCNP (including ours) at high polymer concentration. These few recent reports by us and others may influence the rational design of future SCNP given that the ability to synthesize SCNP at high polymer concentration could open up new and exciting applications (e.g., coating technology), besides allowing for more economical and efficient production of preciselyengineered soft nanoparticles. Thus, we believe it is of paramount importance to gain a better fundamental understanding of our current system as we work towards designing functional SCNP for potential future applications.
Herein, the aims of this work are i) determining the importance of OEG side-chains in linear precursors during the ROP-mediated formation of SCNP at high polymer concentration, ii) establishing alcohol initiator structure-property relationship and iii) investigating the effect of alcohol initiator concentration. To achieve these aims, we have prepared various linear random copolymers that consist of different sidechain functionalities (i.e., poly(oligo(ethylene glycol) acrylate) (P1), polystyrene (P2), and poly(methyl acrylate) (P3)) by RAFT polymerization (Scheme 1b), and their abilities to form SCNP at high polymer concentration are evaluated. To the best of our knowledge, there are few studies that investigate the effects of polymer side-chains in SCNP formation. In addition, three initiators with different molecular architecture and functionality, including benzyl alcohol (monohydroxy), triethylene glycol (dihydroxy) and pentaerythritol ethoxylate (tetrahydroxy) are tested as suitable initiators for nanoparticle formation. All resulting linear copolymers and nanoparticles are extensively characterized by gel-permeation chromatography (GPC), dynamic light scattering (DLS) and proton nuclear magnetic resonance $\left({ }^{1} \mathrm{H}\right.$ NMR $)$ spectroscopy.

Scheme 1. (a) Schematic Representation of the Formation of Nanoparticles from Single Polymer Chains via OrganoCatalyzed Ring-Opening Polymerization. (b) Linear Polymer Precursors (P1-P3) and Alcoholic Initiators Investigated in this Study

a)
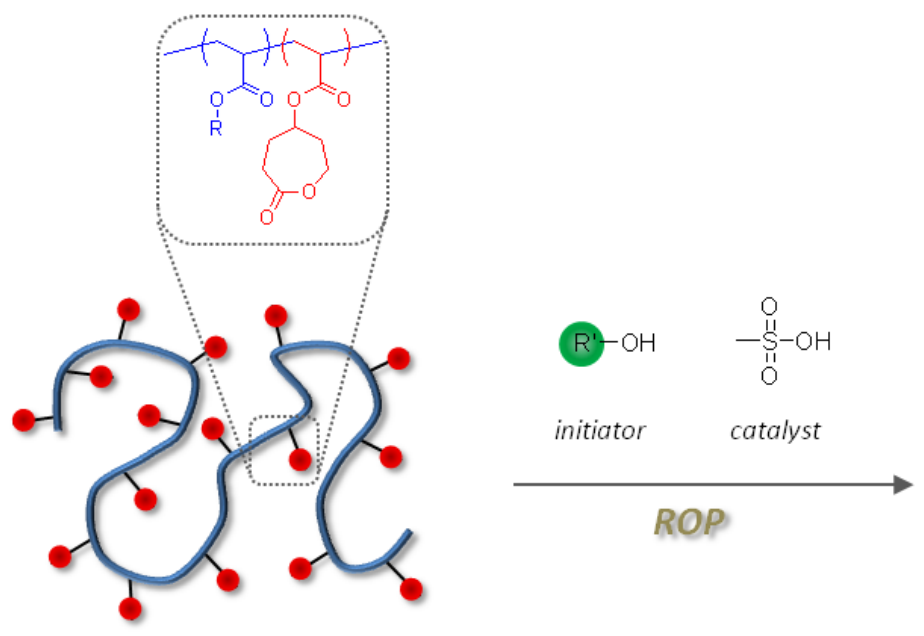

b)

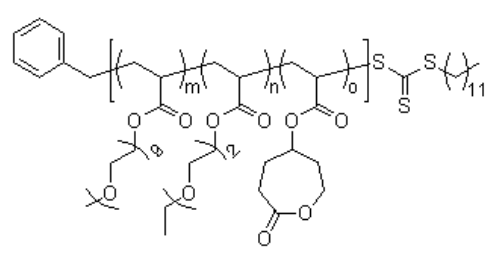

P1

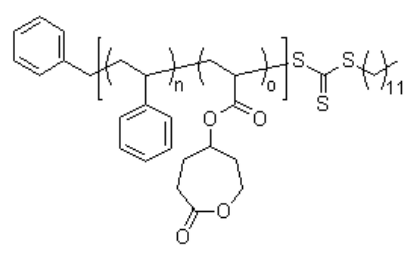

P2
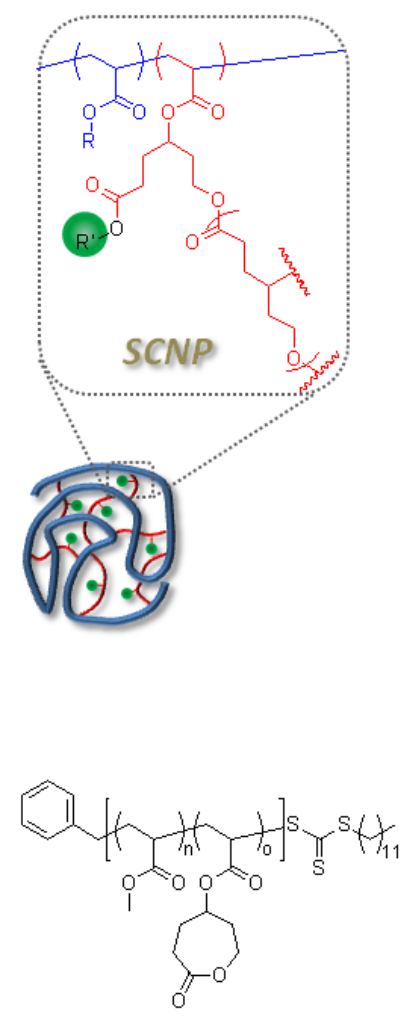

P3
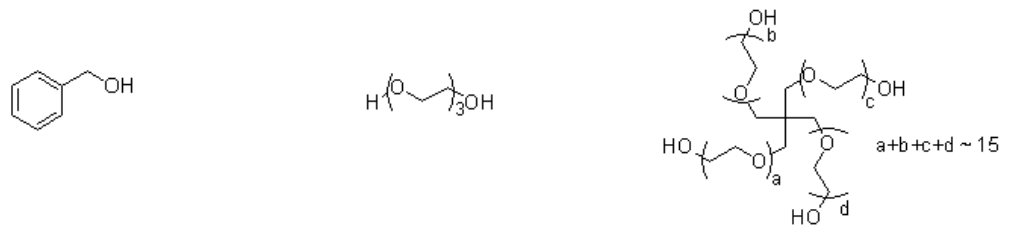


\section{EXPERIMENTAL SECTION}

Materials. 1-Dodecanethiol (Aldrich, $\geq 98 \%$ ), potassium hydroxide $(\mathrm{KOH})$ (Sigma-Aldrich, 90\%, flakes), carbon disulfide (Fluka, $\geq 99 \%$ ), benzyl bromide (Aldrich, 98\%), 1,4cyclohexanediol (Aldrich, 99\%), triethylamine (Scharlau, 99\%), acryloyl chloride (Merck, $\geq 96 \%$ ), pyridinium chlorochromate (Aldrich, 98\%), 3-chloroperoxybenzoic acid (Aldrich, $\geq 77 \%$ ), benzyl alcohol (Sigma-Aldrich, 99.8\%, anhydrous), triethylene glycol (Fluka, $\geq 97 \%$ ), pentaerythritol ethoxylate (Aldrich, $M_{\mathrm{n}} \sim 797 \mathrm{~g} \cdot \mathrm{mol}^{-1}$ ), methanesulfonic acid (Fluka, $\geq 99 \%$ ), 1,4-dioxane (Sigma-Aldrich, $\geq 99 \%$ ) and 2,2'azobis(2-methylpropionitrile) (AIBN) (Acros, 98\%) were used as received. Monomers oligo(ethylene glycol) methyl ether acrylate (Aldrich, $M_{\mathrm{n}}=480 \mathrm{~g} \cdot \mathrm{mol}^{-1}$ ), di(ethylene glycol) ethyl ether acrylate (Aldrich, $\geq 90 \%$ ), methyl acrylate (Aldrich, 99\%) and styrene (Sigma-Aldrich, $\geq 99 \%$ ) were passed over basic alumina to remove inhibitors prior to use. Sodium hydrogen carbonate $\left(\mathrm{NaHCO}_{3}\right)$, sodium sulfate $\left(\mathrm{Na}_{2} \mathrm{SO}_{4}\right.$, anhydrous), celite, methanol $(\mathrm{MeOH})$, ethanol (EtOH), chloroform $\left(\mathrm{CHCl}_{3}\right)$, dichloromethane (DCM), diethyl ether (DEE), hexane, cyclohexane, ethyl acetate, toluene and tetrahydrofuran (THF) were obtained from Chem-Supply and used as received. Magnesium sulfate $\left(\mathrm{MgSO}_{4}\right.$, anhydrous) was obtained from Merck and used as it is. Anhydrous, deoxygenated DCM and THF were obtained by distillation under argon from $\mathrm{CaH}_{2}$ and sodium benzophenone ketyl, respectively. Deuterated chloroform $\left(\mathrm{CDCl}_{3}\right)$ was obtained from Cambridge Isotope Laboratories and used as received. High-purity water with a resistivity of $>18 \mathrm{M} \Omega \cdot \mathrm{cm}$ was obtained from an in-line Millipore $\mathrm{RiOs/Origin} \mathrm{water} \mathrm{purification} \mathrm{system.} \mathrm{The} \mathrm{synthesis} \mathrm{of} \mathrm{4-}$ (acryloyloxy)- $\mathcal{E}$-caprolactone was performed in accordance to literature procedures. ${ }^{50}$ The RAFT agent, benzyl dodecyl carbonotrithioate, was synthesized using the same protocol in our previous publication. ${ }^{45}$

Instrumentation. Polymer molecular weight characterization was carried out via gel-permeation chromatography (GPC) was carried out on a Shimadzu liquid chromatography system equipped with a Wyatt DAWN-HELEOS MALLS detector $(690 \mathrm{~nm}, 30 \mathrm{~mW})$, Wyatt OPTILAB DSP interferometric refractometer $(690 \mathrm{~nm})$ and Shimadzu SPD-10AVP UV-Vis detector using three Phenomenex Phenogel columns (500, 104, and $106 \AA$ porosity; $5 \mu \mathrm{m}$ bead size) operating at 45 ${ }^{\circ} \mathrm{C}$. THF was used as the eluent at a flowrate of $1 \mathrm{~mL} \cdot \mathrm{min}^{-1}$. The molecular weights of all samples were determined using polystyrene standards. All sample solutions were filtered through $0.45 \mu \mathrm{m}$ Teflon syringe filters.

Dynamic light scattering (DLS) measurements were performed on a Wyatt DynaPro NanoStar DLS/SLS instrument with a GaAs laser $(658 \mathrm{~nm})$ at an angle of $90^{\circ}$ and a temperature of $25 \pm 0.1{ }^{\circ} \mathrm{C}$. Stable spectra were obtained at sample concentrations of $1 \mathrm{mg} \cdot \mathrm{mL}^{-1}$ in THF. All sample solutions were filtered through $0.45 \mu \mathrm{m}$ Teflon syringe filters.

${ }^{1} \mathrm{H}$ and ${ }^{13} \mathrm{C}$ nuclear magnetic resonance (NMR) spectroscopy was conducted on a Varian Unity $400 \mathrm{MHz}$ spectrometer operating at $400 \mathrm{MHz}$, using deuterated solvent $\left(\mathrm{CDCl}_{3}\right)$ as reference and a sample concentration of approximately 20 $\mathrm{mg} \cdot \mathrm{mL}^{-1}$.

Synthesis of Linear Polymer Precursors (P1, P2 and P3) via RAFT Polymerization. P1 was synthesized in accordance to our previous publication. ${ }^{45}$
For the synthesis of P2, AIBN (5.7 mg, $34.5 \mu \mathrm{mol})$, benzyl dodecyl carbonotrithioate $(31.9 \mathrm{mg}, 86.2 \mu \mathrm{mol})$, styrene (1.49 $\mathrm{g}, 14.3 \mathrm{mmol})$ and 4-(acryloyloxy)- $\mathcal{E}$-caprolactone $(539 \mathrm{mg}$, $2.93 \mathrm{mmol})$ were first dissolved in 1,4-dioxane $(2 \mathrm{~mL})$. The reaction mixture was degassed by bubbling with $\mathrm{N}_{2}$ for 30 min at $0{ }^{\circ} \mathrm{C}$ in an ice water bath. The reaction mixture was stirred at $75{ }^{\circ} \mathrm{C}$ for $36 \mathrm{~h}$ under $\mathrm{N}_{2}$ and then cooled in an ice bath. The monomer conversion and percentage of lactone moieties in the polymer were determined to be $91 \%$ and $19 \%$, respectively, by ${ }^{1} \mathrm{H}$ NMR spectroscopic analysis. The crude mixture was diluted with THF (6 mL) and precipitated into DEE:hexane: cyclohexane $(1: 1: 1,90 \mathrm{~mL})$, and the precipitate was isolated by centrifugation. This precipitation step was repeated once more and the precipitate was dried in vacuo to afford $\mathbf{P 2}$ as a yellow solid, $1.62 \mathrm{~g}(80 \%)$. GPC and ${ }^{1} \mathrm{H}$ NMR characterization data are shown in Table 1 and Figure S1 of the Supporting Information (SI), respectively.

For the synthesis of P3, AIBN (1.1 mg, $6.90 \mu \mathrm{mol})$, benzyl dodecyl carbonotrithioate $(6.40 \mathrm{mg}, 17.3 \mu \mathrm{mol})$, methyl acrylate $(237 \mathrm{mg}, 2.76 \mathrm{mmol})$ and 4-(acryloyloxy)- $\mathcal{E}$-caprolactone $(127 \mathrm{mg}, 690 \mu \mathrm{mol})$ were first dissolved in 1,4-dioxane $(1.1$ $\mathrm{mL}$ ). The reaction mixture was degassed by bubbling with $\mathrm{N}_{2}$ for $30 \mathrm{~min}$ at $0{ }^{\circ} \mathrm{C}$ in an ice water bath. The reaction mixture was stirred at $75{ }^{\circ} \mathrm{C}$ for $16 \mathrm{~h}$ under $\mathrm{N}_{2}$ and then cooled in an ice bath. The monomer conversion and percentage of lactone moieties in the polymer were determined to be $94 \%$ and $19 \%$, respectively, by ${ }^{1} \mathrm{H}$ NMR spectroscopic analysis. The crude mixture was diluted with THF $(3 \mathrm{~mL})$ and precipitated into DEE:hexane $(7: 3,50 \mathrm{~mL})$, and the precipitate was isolated by centrifugation. This precipitation step was repeated once more and the precipitate was dried in vacuo to afford $\mathbf{P 3}$ as a yellow tacky substance, $290 \mathrm{mg}$ (80\%). GPC and ${ }^{1} \mathrm{H}$ NMR characterization data are shown in Table 1 and Figure S2 of the SI, respectively.

Nanoparticle Formation via ROP. The formation of all nanoparticles follows the same general procedure. Linear polymer precursors (at a lactone concentration of $73 \mathrm{mM}$, which translated to 100,44 and $39 \mathrm{mg} \cdot \mathrm{mL}^{-1}$ for $\mathbf{P 1}, \mathbf{P} 2$ and $\mathbf{P 3}$, respectively), methanesulfonic acid $(1.3 \mu \mathrm{L}, 20 \mu \mathrm{mol})$ and various concentrations of alcoholic initiator were dissolved in 1 $\mathrm{mL}$ of $\mathrm{CDCl}_{3}$, and the reaction mixture was left to react at 25 ${ }^{\circ} \mathrm{C}$ for a day. The reaction mixture was filtered through a Teflon syringe filter $(0.45 \mu \mathrm{m}$ pore size $)$ and precipitated into DEE:hexane $(7: 3,10 \mathrm{~mL})$. The precipitate was subsequently isolated by centrifugation. This precipitation step was repeated once more and the nanoparticles were dried in vacuo. The yield was typically between $60-75 \%$. Noteworthy, both the filtered and unfiltered products of SCNP based on P1 yield identical GPC and DLS traces. However, for P2 and P3, small, macroscopically visible 'gel-like' materials were observed in the reaction mixtures but could not be analyzed effectively via GPC or DLS because of instrument limitations. Hence, the reaction mixtures for $\mathbf{P 2}$ and $\mathbf{P 3}$ have to be filtered prior to analysis. For consistency, all reaction mixtures were therefore filtered prior to purification and analysis.

\section{RESULTS AND DISCUSSION}

Our general strategy in making SCNP involves the combination of advanced polymer synthetic technologies and is divided into two key parts. Firstly, linear random copolymer precursors containing pendent lactone functionalities were made via the RAFT copolymerization of 4 -(acryloyloxy)- $\varepsilon$ - 
caprolactone with other vinyl monomers. The RAFT technique effectively mediates the formation of well-defined linear precursors but more importantly negates the use of metal/ligand catalytic systems that may compromise the lactone functionality. To induce nanoparticle formation, the RAFT-made linear precursors were then cross-linked via organo-catalyzed ROP using an alcohol initiator and methanesulfonic acid, which is known to be an excellent organo-catalyst in regulating the polymerization of lactone monomers. The overall process is metal-free and does not involve complicated synthetic protocols, while the formed linear polymers and nanoparticles are easily purified by simple precipitation procedures. In the following section, the synthesis of various linear precursors with different side-chain functionalities and their abilities to form nanoparticles are described. This is followed by investigations into the effects of alcohol initiator structure and concentration on SCNP formation.

Side-Chain Effect. As mentioned above, we have previously observed the formation of SCNP at high polymer concentration using the model linear precursor P1 that contain OEG side-chains. ${ }^{45}$ To determine if the OEG brushes actually aided the formation of SCNP, two other linear precursors composed

a)

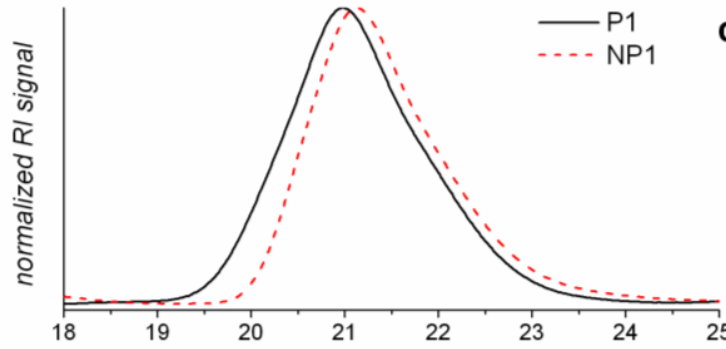

b)

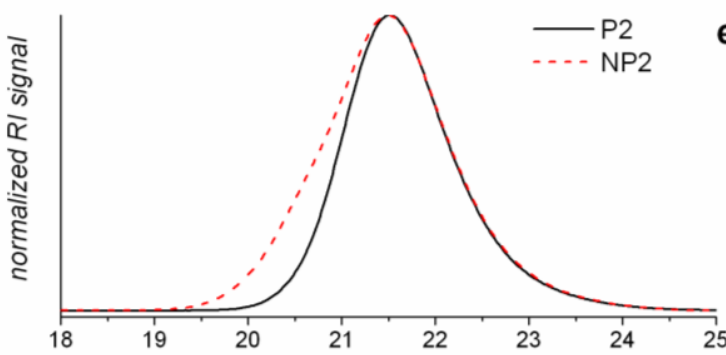

c)

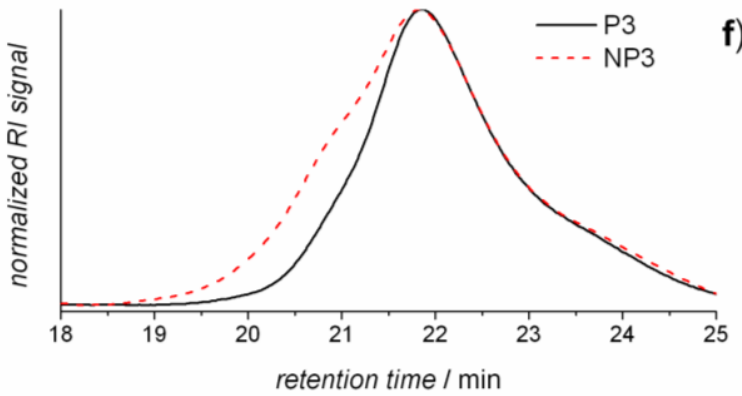

of different side-chains (i.e., phenyl for polystyrene $\mathbf{P 2}$ and methyl ester for poly(methyl acrylate) P3) were made and compared in terms of their abilities to form SCNP at high polymer concentration. For a systematic comparison, linear precursors P1-P3 with the same targeted number-average degree of polymerization $\left(D P_{n}\right)$ of 200 monomer repeat units and 20 $\mathrm{mol} \%$ of lactone moieties per polymer chain were synthesized. In addition, the initial molar ratio of the RAFT agent (benzyl dodecyl carbonotrithioate) to free radical initiator $(2,2$ 'azobis(2-methylpropionitrile) (AIBN)) was kept at a consistent value of 2.5:1. All RAFT polymerizations were taken to near full monomer conversion (> 90\%) as confirmed by ${ }^{1} \mathrm{H}$ NMR analysis. Further ${ }^{1} \mathrm{H}$ NMR analysis of the purified linear polymers (after repetitive precipitation) revealed the successful incorporation of ca. $19 \mathrm{~mol} \%$ of lactone groups per polymer chain. The GPC differential refractive index (DRI) chromatograms of P1-P3 are shown in Figure 1a-c. Overall, the polymerizations were sufficiently well-controlled given that the GPC DRI traces were monomodal, with dispersity $(\nexists)$ values $\leq 1.50$. The number-averaged molecular weight $\left(M_{\mathrm{n}}\right)$ and $D$ values as determined by GPC using polystyrene standards are listed in Table 1.
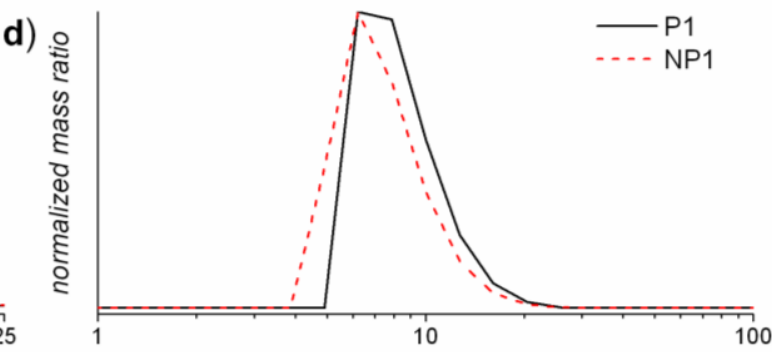

e)
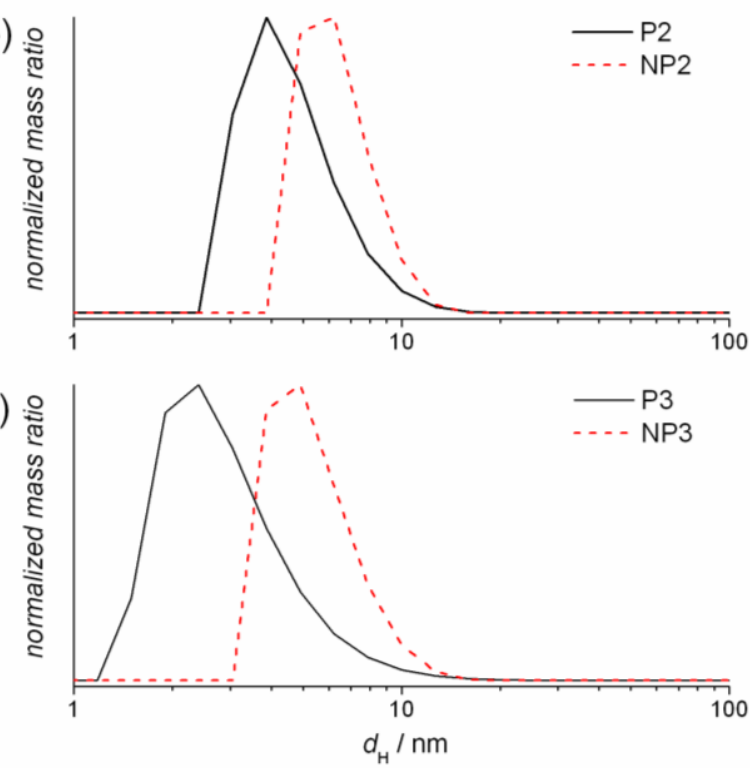

Figure 1. (a-c) GPC DRI chromatograms and (d-f) DLS mass distributions of linear polymer precursors (P1-P3) and the corresponding nanoparticles (NP1-NP3) formed after ROP.

The synthesized linear precursors P1-P3 were subjected to ROP cross-linking using the same 'standard' reaction conditions as our previous publication, i.e. in the presence of benzyl alcohol and methanesulfonic acid in chloroform to afford initiator-to-catalyst-to-lactone molar ratio of 1:2:7.3 and at a total lactone concentration of $73 \mathrm{mM} .^{45}$ In terms of mass concentrations, this translated to 100,44 and $39 \mathrm{mg} \cdot \mathrm{mL}^{-1}$ for $\mathbf{P 1}, \mathbf{P 2}$ and $\mathbf{P 3}$, respectively because of the differences in the molecular weight of the monomers used. For reliable and systematic determination of the side-chain effect, it is imperative that the total lactone concentration and initiator-to-catalyst-to-lactone molar ratio - instead of the polymer mass concentration - are kept the same across all three systems. After $24 \mathrm{~h}$ of ROP, the samples were analyzed by ${ }^{1} \mathrm{H}$ NMR, GPC and DLS. ${ }^{1} \mathrm{H}$ NMR analysis revealed that the lactone groups have been reacted in all cases. Based on the GPC DRI chromatograms of the 
formed nanoparticles NP1-NP3, only NP1 displayed a shift towards higher retention times, indicating the collapse of single polymer chains and the formation of SCNP whereas both NP2 and NP3 showed opposite trends that indicated the formation of higher molecular weight species as their GPC DRI chromatograms shifted toward lower retention times. This observation was corroborated by multiangle laser light scattering (MALLS) analysis (Figure S1 of the Supporting Information (SI)). DLS measurements of the linear precursors and their corresponding nanoparticles also correlated with the trends observed in GPC (Figure 1d-f; Table 1). The formed NP1 has a smaller hydrodynamic diameter $\left(d_{\mathrm{H}}\right)$ than its linear precursor P1 (7.6 vs $8.1 \mathrm{~nm}$ ). On the other hand, both NP2 and NP3 have larger $d_{\mathrm{H}}$ values of 5.8 and $6.0 \mathrm{~nm}$ compared to 4.8 and $3.2 \mathrm{~nm}$ for $\mathbf{P 2}$ and $\mathbf{P 3}$, respectively. Taken together, the combination of GPC and DLS analysis clearly demonstrated that only P1 was able to form SCNP whereas both P2 and P3 resulted in multi-chain nanoparticles (due to interpolymer coupling reactions). These results proved that OEG sidechains indeed play a key role in aiding the formation of SCNP at high polymer concentration. We hypothesize that the OEG side-chains are sterically shielding and isolating single polymer chains, thereby preventing interpolymer aggregation while facilitating intramolecular cross-linking reactions. Since the linear precursor $\mathbf{P} \mathbf{1}$ has excellent solubility in the reaction media $\left(\mathrm{CDCl}_{3}\right)$, the possibility of a precipitation-aided SCNP formation is ruled out.

Table 1. Number-Averaged Molecular Weight, Dispersity and Hydrodynamic Diameter of Synthesized Polymers and Nanoparticles

\begin{tabular}{lccc}
\hline polymer & $M_{\mathrm{n}}\left(\mathrm{g} \cdot \mathrm{mol}^{-1}\right)$ & $D$ & $d_{\mathrm{H}}(\mathrm{nm})$ \\
\hline P1 & 51000 & 1.47 & 8.12 \\
NP1 $^{a}$ & 45000 & 1.41 & 7.56 \\
P2 $_{\text {NP2 }}$ & 23300 & 1.17 & 4.80 \\
P3 $_{\text {NP3 }}$ & 27300 & 1.25 & 5.80 \\
NP1 $_{20 H}$ & 22000 & 1.50 & 3.20 \\
NP1 $_{40 H}$ & 25100 & 1.60 & 6.00 \\
NP1 $_{2 \mathbf{m M}}$ & 46000 & 1.47 & 7.58 \\
NP1 $_{\mathbf{2 0 m M}}$ & 45500 & 1.42 & 7.66 \\
NP1 $_{\mathbf{1 0 0 m M}}$ & 43200 & 1.19 & 6.60 \\
\hline
\end{tabular}

${ }^{a}$ NP1 is defined as the reference SCNP in this study that was formed under 'standard' conditions and is used for comparison with other SCNP. Therefore, NP1 is the same as NP1 $\mathbf{1}_{\mathbf{O H}}$ and $\mathrm{NP1}_{10 \mathrm{mM}}$ (i.e., $\mathbf{N P 1}=\mathrm{NP1}_{1 \mathrm{OH}}=\mathbf{N P 1} 1_{10 \mathrm{mM}}$ ).

To further highlight the importance of OEG side-chains, it is worthwhile comparing our findings with two other independent reports by Terashima, Sawamoto et. al. ${ }^{39}$ and Palmans, Voets et. al. ${ }^{33}$ who also witnessed the formation of SCNP at high polymer concentration in their systems using OEG-based linear precursors (Figure 2). In the work by Terashima, Sawamoto et. al., ${ }^{39}$ amphiphilic linear random copolymers consisting of OEG side-chains and hydrophobic functional groups $\left(\mathbf{P}_{\mathbf{A}}\right)$ were made and underwent single-chain selffolding in water based on hydrophobic physical interactions to form SCNP. They observed the formation of SCNP at a polymer concentration range of $1-60 \mathrm{mg} \cdot \mathrm{mL}^{-1}$. Concurrently, Pal- mans, Voets et. al. ${ }^{33}$ reported the formation of dynamic SCNP based on hydrogen bonding using a linear random copolymer composed of OEG side-chains and benzene-1,3,5tricarboxamides $\left(\mathbf{P}_{\mathbf{B}}\right)$. For this system, they demonstrated the formation of SCNP at $100 \mathrm{mg} \cdot \mathrm{mL}^{-1}$. The $\mathrm{OEG}$ side-chains clearly played a key role, as it cannot be a mere coincidence that the formation of SCNP at high polymer concentration occurred when OEG-based linear precursors were used - especially considering that this was observed in three distinctive chemical systems.

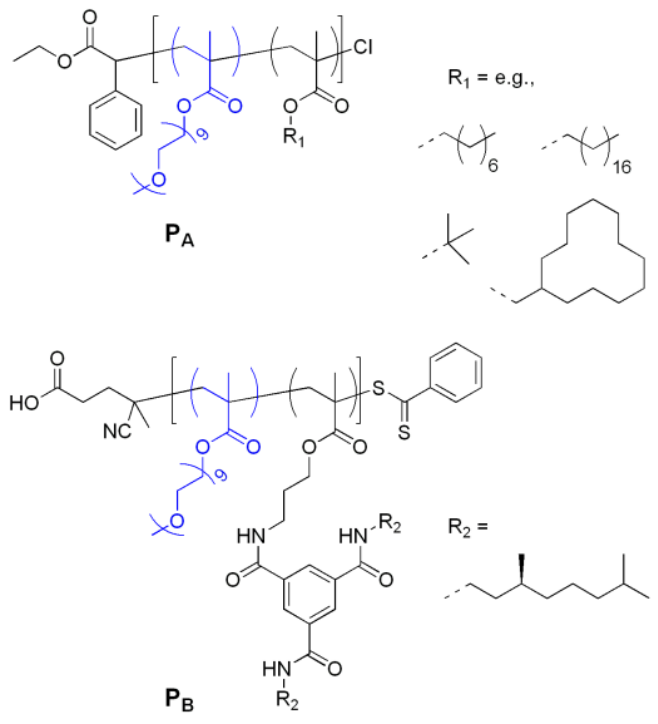

Figure 2. Examples of other OEG-based polymer chains employed by Terashima, Sawamoto and co-workers $\left(\mathbf{P}_{\mathbf{A}}\right)^{39}$ and Palmans, Voets and co-workers $\left(\mathbf{P}_{\mathbf{B}}\right)^{33}$ in the formation of SCNP at high polymer concentration.

Initiator Structure Effect. Following on from the investigation into the effect of polymer side-chains, the influence of the initiator structure was also studied. For this, we have employed benzyl alcohol (monohydroxy), triethylene glycol (dihydroxy) and pentaerythritol ethoxylate (tetrahydroxy) as initiators in the ROP of P1 where the initial concentration of hydroxyl groups are kept constant for each initiator system and using the same standard conditions as above (i.e., at hydroxyl-to-catalyst-to-lactone molar ratio of $1: 2: 7.3$ and at a total lactone concentration of $73 \mathrm{mM}$ ).

Figure $3 \mathrm{a}$ and $\mathrm{b}$ show the GPC DRI chromatograms and DLS mass distributions of $\mathbf{P 1}$ and the formed SCNP NP1 $\mathbf{1}_{\mathbf{1 0 H}}$, $\mathbf{N P 1}_{2 \mathrm{OH}}$ and $\mathbf{N P 1}_{4 \mathrm{OH}}$ using different multifunctional alcohol initiators (note: $\mathbf{N P 1}_{\mathbf{x O H}}$ where $\mathrm{X}$ denotes the number of hydroxyl groups attached per initiator). The initiator structure does not seem to affect the formation of SCNP as the GPC DRI chromatograms of the nanoparticles look almost identical, with only minute differences in their $M_{\mathrm{n}}$ values (from 45 to 46 $\left.\mathrm{kg} \cdot \mathrm{mol}^{-1}\right)$. The GPC MALLS chromatograms yielded similar results (Figure S2). DLS results were also in agreement with the GPC data as the $d_{\mathrm{H}}$ values of the SCNP showed little variation and range from 7.6 to $7.7 \mathrm{~nm}$. Regardless of the initiator structure, SCNP were obtained instead of interpolymer aggregates because the products are smaller in size compared to the linear precursor. 
a)

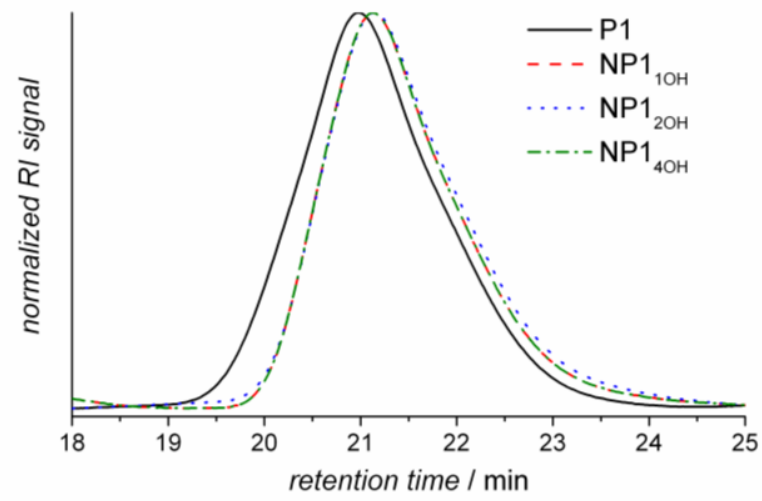

b)

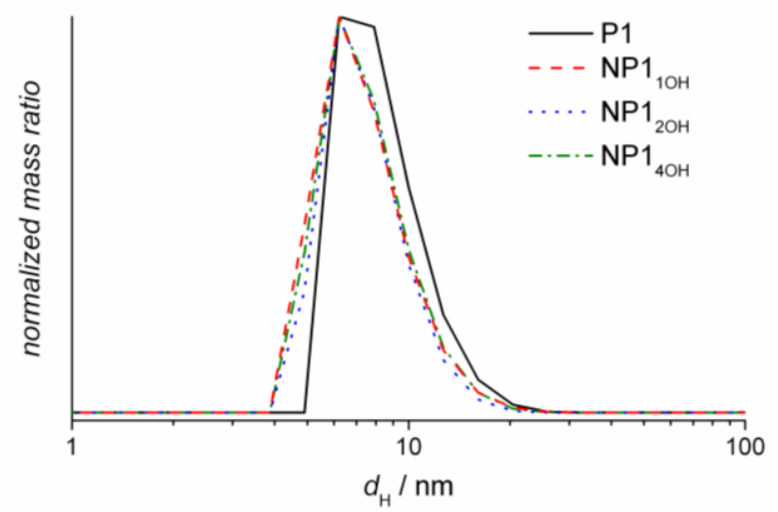

Figure 3. (a) GPC DRI chromatograms and (b) DLS mass distributions of linear polymer precursor P1 and SCNP formed using various types of alcohol initiators.

The ${ }^{1} \mathrm{H}$ NMR spectra of P1 and SCNP NP1 $1_{10 H}, \mathbf{N P 1}_{2}$ OH and $\mathbf{N P 1}_{40 \mathrm{H}}$ are shown in Figure 4. NMR spectroscopic analysis of the nanoparticles revealed that resonance $\mathrm{b}$ of the caprolactone groups in P1 quantitatively shifted from $\delta_{\mathrm{H}} 4.30-4.50$ to 4.00 $4.28 \mathrm{ppm}$ after $21 \mathrm{~h}$ of ROP, overlapping with the methylene protons from other ester groups. The integral of the area under the ester resonance at $\delta_{\mathrm{H}} 4.00-4.28 \mathrm{ppm}$ also increased correspondingly as the linear precursor P1 was converted to nanoparticles. In addition, resonance a that corresponds to the methanetriyl protons broadened (resonance a') and possibly shifted from $\delta_{\mathrm{H}} 4.90-5.10$ to $4.50-4.65 \mathrm{ppm}$ (resonance X). However, we are still not entirely sure on the precise assignment of resonance $\mathrm{X}$ at the moment except for the fact that this resonance most likely corresponds to protons belonging to ester functionalities. This is based on the observation that the appearance of resonance $\mathrm{X}$ became more prominent as the ROP progresses which coincides with the formation of growing polyester linkages (Figure S3). Noteworthy, the monomer 4(acryloyloxy)- $\mathcal{E}$-caprolactone used in the synthesis of $\mathbf{P 1}$ consisted of both cis- and trans- isomers, which may explain for the different chemical shifts observed for resonances a' and $\mathrm{X}$ in the ${ }^{1} \mathrm{H}$ NMR spectra after ROP. Regardless, based on the NMR analysis, quantitative ring-opening of the caprolactones was achieved in all cases.

Kinetic studies were also performed to monitor the progress of ROP via ${ }^{1} \mathrm{H}$ NMR analysis based on the disappearance of the area under resonance $b$ (Figure 5). The kinetic profiles for all three nanoparticles $\left(\mathbf{N P 1} 1_{10 H}, \mathbf{N P 1} 1_{20 H}\right.$ and $\left.\mathbf{N P 1} 1_{40 H}\right)$ follow a similar exponential decay and first-order kinetics behavior, in accordance with the general features of controlled chaingrowth polymerization. Based on the kinetic plots, near com- plete (> 90\%) ring-opening of the caprolatones were realized after $10 \mathrm{~h}$ of reaction time for all cases.

a)

b)
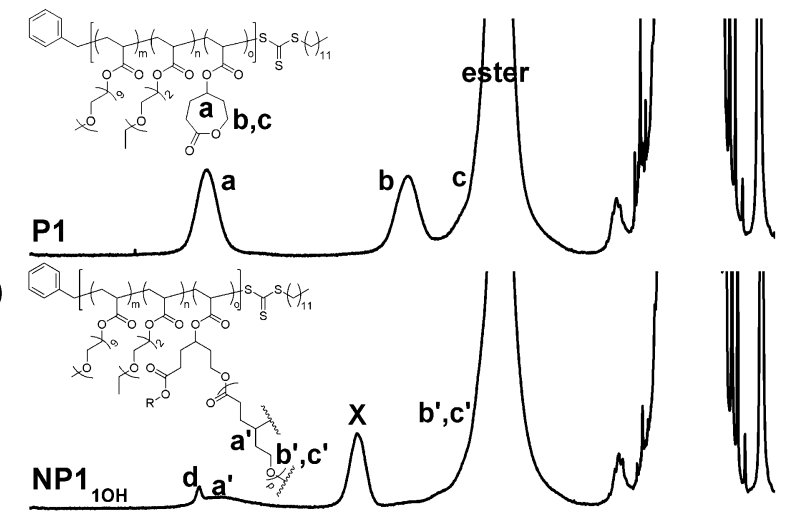

c)

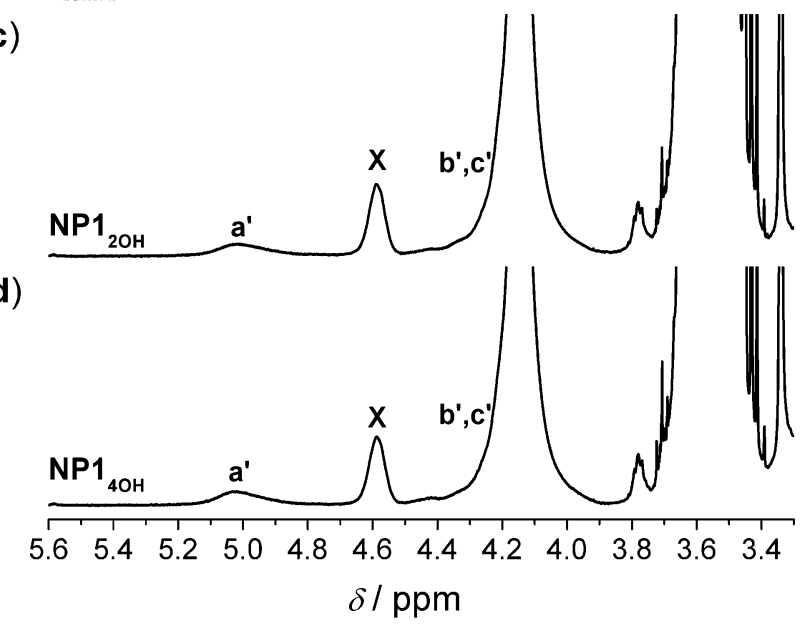

Figure 4. ${ }^{1} \mathrm{H}$ NMR spectra of (a) P1 and SCNP formed using: (b) benzyl alcohol (NP1 $\left.\mathbf{1}_{\mathbf{1 O H}}\right)$; (c) triethylene glycol (NP1 $\left.\mathbf{N}_{\mathbf{2 O H}}\right)$ and; (d) pentaerythritol ethoxylate $\left(\mathbf{N P 1}_{\mathbf{4 O H}}\right)$. Resonances that correspond to the key functional groups are labeled. Resonance d corresponds to the methylene protons of the benzyl groups in $\mathbf{N P} \mathbf{1}_{\mathrm{OH}}$.

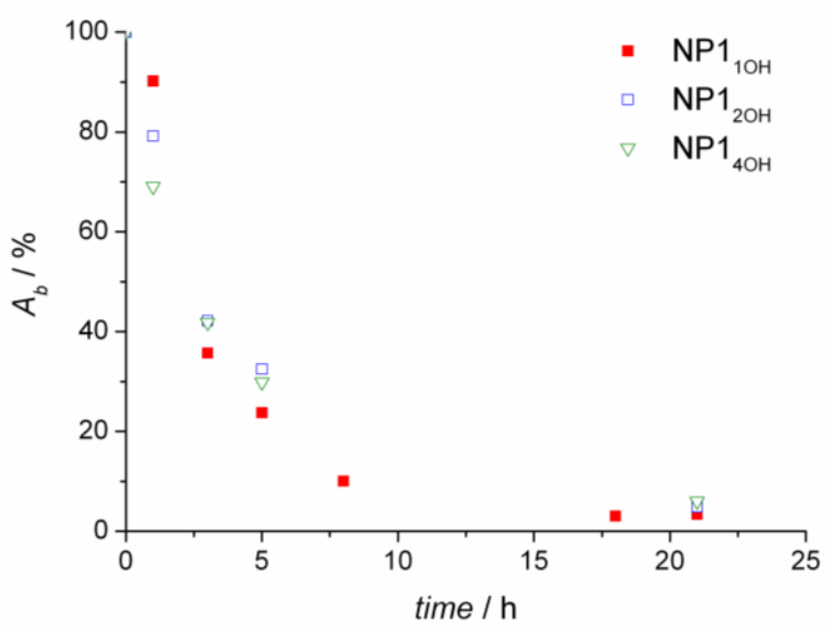

Figure 5. Kinetic profiles of SCNP formation with different types of alcoholic initiators (based on the disappearance of the area under resonance $\mathrm{b}\left(A_{\mathrm{b}}\right)$ ), as monitored by ${ }^{1} \mathrm{H}$ NMR analysis.

Initiator Concentration Effect. Given that the formation of SCNP is essentially a polymerization process, the alcohol initiator concentration should influence the extent of cross- 
linking in a similar way to other polymer cross-linking systems. To validate this, different concentrations of benzyl alcohol were employed in the ROP of P1 at various initiator-tocatalyst-to-lactone molar ratios (i.e., 0.2:2:7.3, 1:2:7.3, 2:2:7.3 and 10:2:7.3). The total lactone concentration (i.e., at $73 \mathrm{mM}$, $100 \mathrm{mg} \cdot \mathrm{mL}^{-1}$ of P1) and all other conditions remained the same.

GPC DRI chromatograms of $\mathbf{P 1}$ and the formed SCNP $\mathbf{N P 1}_{2 \mathrm{mM}}, \mathbf{N P 1}_{10 \mathrm{mM}}, \mathbf{N P 1}_{20 \mathrm{mM}}$ and $\mathbf{N P 1}_{100 \mathrm{mM}}$ are shown in Figure 6a (note: $\mathbf{N P 1} \mathbf{X m M}_{\mathbf{X m}}$ where $\mathrm{X}$ denotes the concentration of benzyl alcohol). The DRI traces of the nanoparticles are different from that of $\mathbf{P 1}$ and in line with the formation of SCNP. However, the DRI traces of the SCNP appeared indistinguishable from one another, except for a slight difference with nanoparticles $\mathbf{N P 1}_{2 \mathrm{mM}}$ that was made with the lowest concentration of benzyl alcohol. The $M_{\mathrm{n}}$ of $\mathbf{N P 1 _ { 2 m M }}$ was determined as $43 \mathrm{~kg} \cdot \mathrm{mol}^{-1}$ compared to ca. $46 \mathrm{~kg} \cdot \mathrm{mol}^{-1}$ for the other SCNP. The GPC MALLS trace of $\mathbf{N P 1}_{2 \mathrm{mM}}$ also seemed to indicate the formation of smaller-sized nanoparticles compared to the other SCNP (Figure S4). DLS analysis provided a clearer comparison amongst the SCNP as the mass distribution of $\mathbf{N P 1}_{\mathbf{2 m M}}$ is distinctively different from the rest, with a measured $d_{\mathrm{H}}$ value of $6.6 \mathrm{~nm}$ compared to 7.6-7.7 $\mathrm{nm}$ for the other SCNP. a)

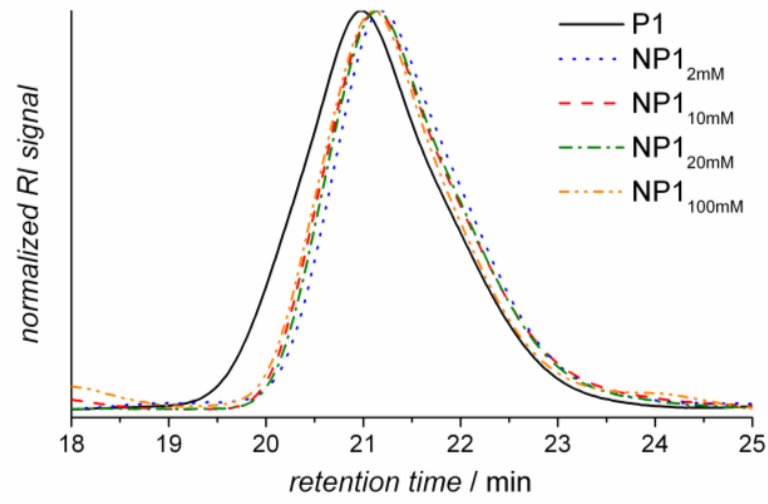

b)

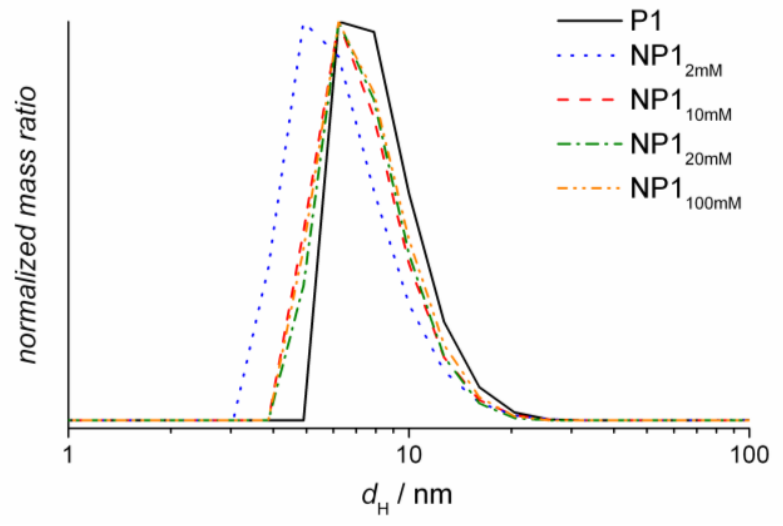

Figure 6. (a) GPC DRI chromatograms and (b) DLS mass distributions of P1 and SCNP formed with various concentrations of benzyl alcohol.

In theory, lowering the initiator concentration would increase the $D P_{\mathrm{n}}$ of polycaprolactone, thereby resulting in a more compact and smaller SCNP. This is because with lesser amounts of initiator, the extent of 'threading' or linking across cross-linkable groups from an initiation point is greater, essentially 'pulling' and bounding the main chain closer together. Consider the alternative scenario where the initiator concentration is higher (e.g, in excess compared to the lactone concen- tration), the number of ring-opened lactone groups per initiation point would be lower and hence lesser cross-linking between the cross-linkable groups. This can cause the main chain to adopt a less compact and more open structure. Thus, it made sense that $\mathbf{N P 1}_{2 \mathrm{mM}}$ is smallest compared to the other SCNP but it was also interesting to note that the sizes of the nanoparticles did not differ at higher initiator concentrations.

NMR spectroscopic analysis of the nanoparticles showed distinctive levels of incorporation of benzyl alcohol into the SCNP structure as the initiator concentration was varied (Figure 7). The intensity of resonance $d$ that corresponds to the methylene protons of the benzyl groups increased with increasing initiator concentration. Based on the area under the peak of resonance d, the $D P_{\mathrm{n}}$ of polycaprolactone for the nanoparticles were determined and found to deviate from the theoretical values especially at higher initiator concentrations (Table 2). At a benzyl alcohol concentration of $2 \mathrm{mM}$, the calculated $D P_{\mathrm{n}}$ based on ${ }^{1} \mathrm{H}$ NMR analysis $\left(D P_{\mathrm{n}}{ }^{\mathrm{NMR}}\right)$ was 40 , which is close to the theoretical $D P_{\mathrm{n}}\left(D P_{\mathrm{n}}^{\text {theo }}\right)$ value of 37 . The initiator efficiency (defined as the ratio of $D P_{\mathrm{n}}^{\mathrm{NMR}}$ to $D P_{\mathrm{n}}^{\text {theo }}$ ) was ca. $91 \%$. However, when the initiator concentration was increased to 10 and $20 \mathrm{mM}$, the $D P_{\mathrm{n}}{ }^{\text {NMR }}$ values were determined as 23 and 15 respectively, ca. three times higher than their $D P_{\mathrm{n}}^{\text {theo }}$ values. The deviation was more apparent when the initiator concentration was increased to $100 \mathrm{mM}$ (in excess compared to the lactone concentration of $73 \mathrm{mM}$ ), where the $D P_{\mathrm{n}}^{\text {NMR }}$ was 8 , ca. eight times higher than its $D P_{\mathrm{n}}^{\text {theo }}$ value. Even though the initiator concentration was varied substantially between $2-100 \mathrm{mM}$, the $D P_{\mathrm{n}}^{\mathrm{NMR}}$ values did not changed considerably (40-8). This may help explain the results obtained by GPC and DLS. Since the $D P_{\mathrm{n}}{ }^{\mathrm{NMR}}$ values only varied moderately (from 23 to 8 ) for benzyl alcohol concentrations of 10,20 and $100 \mathrm{mM}$, the lack of size differences between nanoparticles $\mathbf{N P 1}_{10 \mathrm{mM}}, \mathbf{N P 1}_{\mathbf{2 0} \mathrm{mM}}$ and $\mathbf{N P 1 _ { 1 0 0 m M }}$ is unsurprising as the change in $D P_{\mathrm{n}}$ of polycaprolactone within this range may not be enough to induce significant particle size variations. The only appreciable decrease in nanoparticle size was observed for $\mathbf{N P 1}_{2 \mathrm{mM}}$ at $D P_{\mathrm{n}}{ }^{\mathrm{NMR}}$ of 40 , i.e. when one initiator molecule was responsible in polymerizing all the caprolactone groups on a single polymer chain. This suggests that to ensure maximum collapse and cross-linking of SCNP, the molar ratio of initiator to main chain should ideally be ca. 1:1.

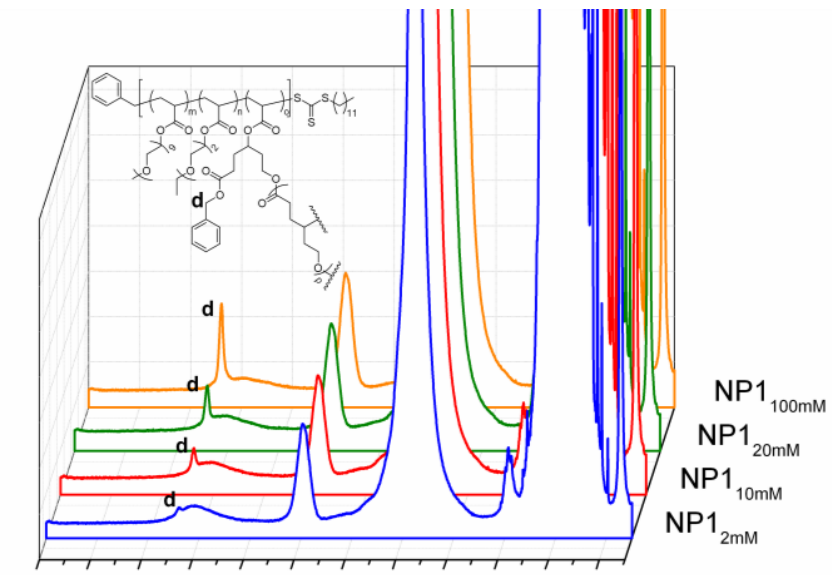

$\begin{array}{llllllllllll}5.6 & 5.4 & 5.2 & 5.0 & 4.8 & 4.6 & 4.4 & 4.2 & 4.0 & 3.8 & 3.6 & 3.4\end{array}$ $\delta / \mathrm{ppm}$

Figure 7. Overlay of the ${ }^{1} \mathrm{H}$ NMR spectra of the SCNP formed with different concentrations of benzyl alcohol. 
The most plausible explanation for the poor initiation efficiency observed at higher initiator concentrations $(\geq 10 \mathrm{mM})$ could be due to faster rate of propagation to initiation. Once initiated, it is highly likely for the growing polycaprolactone to react with other adjacent caprolactone groups faster than a new initiator molecule could initiate a new growing chain taking into account the caprolactone groups within the same main chain are in close proximity to one another and in a confined space.

Table 2. Average Number of Repeat Units in Polycaprolactone Linkages

\begin{tabular}{lccc}
\hline polymer & $D P_{\mathrm{n}}^{\text {NMR }}$ & $D P_{\mathrm{n}}^{\text {theo }}$ & efficiency $^{a}(\%)$ \\
\hline NP1 $_{\mathbf{2 m M}}$ & 40 & 37 & 91 \\
NP1 $_{10 \mathrm{mM}}$ & 23 & 7 & 32 \\
NP1 $_{\mathbf{2 0 m}}$ & 15 & 4 & 25 \\
NP1 $_{100 \mathrm{mM}}$ & 8 & 1 & 10
\end{tabular}

${ }^{a}$ Defined as the ratio of $D P_{\mathrm{n}}{ }^{\mathrm{NMR}}$ to $D P_{\mathrm{n}}^{\text {theo }}$.

\section{CONCLUSIONS}

We report herein an in-depth investigation into the factors affecting the formation of SCNP prepared via organocatalyzed ROP. Specifically, we investigated the effect of i) side-chain functionalities on linear random copolymer precursors, ii) initiator structure and iii) initiator concentration. For this investigation, we have synthesized various linear precursors containing reactive pendent caprolactone groups including OEG-based copolymers (P1), polystyrene (P2) and poly(methyl acrylate) (P3), and have employed multifunctional alcohol initiators in the ROP-mediated formation of SCNP. We found that only P1 successfully formed SCNP at high polymer concentration (ca. $100 \mathrm{mg} \cdot \mathrm{mL}^{-1}$ ) while $\mathbf{P 2}$ and $\mathbf{P 3}$ resulted in multi-chain aggregates. This crucially demonstrated the importance of OEG brushes in aiding the formation of SCNP at high polymer concentration. Meanwhile, the architecture of the alcohol initiator has no affect on nanoparticle formation. However, the initiator concentration influenced the SCNP formation step as a smaller and more compact SCNP was produced when the initiator and linear precursor were set at equimolar concentration. The ability to prepare SCNP at high polymer concentrations has many advantages and may lead to exciting applications (e.g., coating technologies). Overall, we envisage that this study will lead to the development of new SCNP for targeted applications. Work is currently underway in our labs in determining the efficacy of SCNP for membrane technologies and bioapplications.

\section{ASSOCIATED CONTENT}

\section{Supporting Information}

Contains additional NMR, MALLS and DLS data. This material is available free of charge via the Internet at http://pubs.acs.org.

\section{AUTHOR INFORMATION}

\section{Corresponding Author}

* Email: gregghq@unimelb.edu.au

\section{ACKNOWLEDGMENT}

The authors acknowledge the Australian Research Council under the Future Fellowship scheme (FT110100411, G.G.Q.) for financial support of this work. E.H.H.W. acknowledges the receipt of a
2014 Early Career Researcher Grant from The University of Melbourne. The authors would like to thank Dr. Jing M. Ren for valuable discussions.

\section{REFERENCES}

(1) Arruebo, M; Fernandez-Pacheco, R.; Ibarra, M. R.; Santamaria, J. Nano Today 2007, 2, 22-32.

(2) Farokhzad, O. C.; Cheng, J.; Teply, B. A.; Sherifi, I.; Jon, S.; Kantoff, P. W.; Richie, J. P.; Langer, R. Proc. Natl. Acad. Sci. U.S.A. 2006, 103, 6315-6320.

(3) Cho, K.; Wang, X.; Nie, S.; Chen, Z. G.; Shin, D. M. Clin. Cancer Res. 2008, 14, 1310-1316.

(4) Terashima, T.; Kamigaito, M.; Baek, K. Y.; Ando, T.; Sawamoto, M. J. Am. Chem. Soc. 2003, 125, 5288-5289.

(5) Fu, Q.; Wong, E. H. H.; Kim, J.; Scofield, J. M. P.; Gurr, P. A.; Kentish, S. E.; Qiao, G. G. J. Mater. Chem. A. 2014, 2, 17751-17756.

(6) Nederberg, F.; Zhang, Y.; Tan, J. P. K.; Xu, K.; Wang, H.; Yang, C.; Gao, S.; Guo, X. D.; Fukushima, K.; Li, L.; Hedrick, J. L.; Yang, Y. -Y. Nat. Chem. 2011, 3, 409-414.

(7) Li, P.; Zhou, C.; Rayatpisheh, S.; Ye, K.; Poon, Y. F.; Hammond, P. T.; Duan, H.; Chan-Park, M. B. Adv. Mater. 2012, 24, 41304137.

(8) Kamigaito, M.; Ando, T.; Sawamoto, M. Chem. Rev. 2001, 101, 3689-3745.

(9) (a) Matyjaszewski, K.; Xia, J. H. Chem. Rev. 2001, 101, 2921; (b) Matyjaszewski, K. Isr. J. Chem. 2012, 52, 206.

(10) Zhang, Q.; Wilson, P.; Li, Z.; McHale, R.; Godfrey, J.; Anastasaki, A.; Waldron, C.; Haddleton, D. M. J. Am. Chem. Soc. 2013, $135,7355-7363$.

(11) Rosen, B. M.; Percec, V. Chem. Rev. 2009, 109, 5069-5119.

(12) (a) Moad, G.; Rizzardo, E.; Thang, S. H. Aust. J. Chem. 2005, 58, 379-410; (b) Moad, G.; Rizzardo, E.; Thang, S. H. Aust. J. Chem. 2009, 62, 1402-1472.

(13) (a) Nederberg, F.; Connor, E. F.; Moller, M.; Glauser, T.; Hedrick, J. L. Angew. Chem. Int. Ed. 2001, 40, 2712-2715; (b) Connor, E. F.; Nyce, G. W.; Myers, M.; Mock, A.; Hedrick, J. L. J. Am. Chem. Soc. 2002, 124, 914-915; (c) Nyce, G. W.; Glauser, T.; Connor, E. F.; Mock, A.; Waymouth, R. M.; Hedrick, J. L. J. Am. Chem. Soc. 2003, 125, 3046-3056; (d) Dove, A. P.; Pratt, R. C.; Lohmeijer, B. G. G.; Waymouth, R. M.; Hedrick, J. L. J. Am. Chem. Soc. 2005, 127, 13798-13799; (e) Pratt, R. C.; Lohmeijer, B. G. G.; Long, D. A.; Waymouth, R. M.; Hedrick, J. L. J. Am. Chem. Soc. 2006, 128, 45564557.

(14) Dove, A. P. ACS Macro Lett. 2012, 1, 1409-1412.

(15) Blencowe, A.; Tan, J. F.; Goh, T. K.; Qiao, G. G. Polymer 2009, 50, 5-32.

(16) Gao, H.; Matyjaszewski, K. Prog. Polym. Sci. 2009, 34, $317-$ 350 .

(17) Wong, E. H. H.; Blencowe, A.; Qiao, G. G. Polym. Chem. 2013, 4, 4562-4565.

(18) Sulistio, A.; Widjaya, A.; Blencowe, A.; Zhang, X.; Qiao, G. G. Chem. Commun. 2011, 47, 1151-1153.

(19) Barner, L.; Davis, T. P.; Stenzel, M. H.; Barner-Kowollik, C. Macromol. Rapid Commun. 2007, 28, 539-559.

(20) Petzetakis, N.; Robin, M. P.; Patterson, J. P.; Kelley, E. G.; Cotanda, P.; Bomans, P. H. H.; Sommerdijk, N. A. J. M.; Dove, A. P.; Epps, T. H.; O’Reilly, R. K. ACS Nano 2013, 7, 1120-1128.

(21) Karagoz, B.; Esser, L.; Duong, H. T.; Basuki, J. S.; Boyer, C.; Davis, T. P. Polym. Chem. 2014, 5, 350-355.

(22) Discher, D. E.; Eisenberg, A. Science 2002, 297, 967-973.

(23) Elsabahy, M.; Wooley, K. L. Chem. Soc. Rev. 2012, 41, $2545-$ 2561.

(24) Utama, R. H.; Drechsler, M.; Forster, S.; Zetterlund, P. B.; Stenzel, M. H. ACS Macro Lett. 2014, 3, 935-939.

(25) Aiertza, M. K.; Odriozola, I.; Cabanero, G.; Grande, H. -J.; Loinaz, I. Cell. Mol. Life Sci. 2012, 69, 337-346.

(26) Altintas, O.; Barner-Kowollik, C. Macromol. Rapid Commun. 2012, 33, 958-971.

(27) Ouchi, M.; Badi, N.; Lutz, J. -F.; Sawamoto, M. Nat. Chem. 2011, 3, 917-924. 
(28) Mecerreyes, D.; Lee, V.; Hawker, C. J.; Hedrick, J. L.; Wursch, A.; Volsken, W.; Magbitang, T.; Huang, E.; Miller, R. D. Adv. Mater. 2001, 13, 204-208.

(29) Cherian, A. E.; Sun, F. C.; Sheiko, S. S.; Coates, G. W. J. Am. Chem. Soc. 2007, 129, 11350-11351.

(30) Forster, E. J.; Berda, E. B.; Meijer, E. W. J. Am. Chem. Soc. 2009, 131, 6964-6966.

(31) Frank, P. G.; Tuten, B. T.; Prasher, A.; Chao, D.; Berda, E. B. Macromol. Rapid Commun. 2013, 35, 249-253.

(32) Appel, E. A.; Dyson, J.; del Barrio, J.; Walsh, Z.; Scherman, O. A. Angew Chem. Int. Ed. 2012, 51, 4185-4189.

(33) Stals, P. J. M.; Gillissen, M. A. J.; Paffen, T. F. E.; de Greef, T. F. A.; Lindner, P.; Meijer, E. W.; Palmans, A. R. A.; Voets, I. K. Macromolecules 2014, 47, 2947-2954.

(34) Altintas, O.; Krolla-Sidenstein, P.; Gliemann, H.; BarnerKowollik, C. Macromolecules 2014, 47, 5877-5888.

(35) Hansell, C. F.; Lu, A.; Patterson, J. P.; O'Reilly, R. K. Nanoscale 2014, 6, 4102-4107.

(36) Willenbacher, J.; Wuest, K. N. R.; Mueller, J. O.; Kaupp, M.; Wagenknecht, H. -A.; Barner-Kowollik, C. ACS Macro Lett. 2014, 3, 574-579.

(37) Ormategui, N.; Garcia, I.; Padro, D.; Cabanero, G.; Grande, H. J.; Loinaz, I. Soft Matter 2012, 8, 734-740.

(38) Murray, B. S.; Fulton, D. A. Macromolecules 2011, 44, 7242 7252.

(39) Terashima, T.; Sugita, T.; Fukae, K.; Sawamoto, M. Macromolecules 2014, 47, 589-600.

(40) Dirlam, P. T.; Kim, H. J.; Arrington, K. J.; Chung, W. J.; Sahoo, R.; Hill, L. J.; Costanzo, P. J.; Theato, P.; Char, K.; Pyun, J. Polym. Chem. 2013, 4, 3765-3773.

(41) Li, W.; Kuo, C. -H.; Kanyo, I.; Thanneeru, S.; He, J. Macromolecules 2014, 47, 5932-5941.

(42) Perez-Baena, I.; Barroso-Bujans, F.; Gasser, U.; Arbe, A.; Moreno, A. J.; Colmenero, J.; Pomposo, J. A. ACS Macro Lett. 2013, 2, 775-779.

(43) Tuten, B. T.; Chao, D.; Lyon, C. K.; Berda, E. B. Polym. Chem. 2012, 3, 3068-3071.

(44) Sanchez-Sanchez, A.; Arbe, A.; Colmenero, J.; Pomposo, J. A. ACS Macro Lett. 2014, 3, 439-443.

(45) Wong, E. H. H.; Lam, S. J.; Nam, E.; Qiao, G. G. ACS Macro Lett. 2014, 3, 524-528.

(46) Altintas, O.; Lejeune, E.; Gerstel, P.; Barner-Kowollik, C. Polym. Chem. 2012, 3, 640-651.

(47) Lyon, C. K.; Prasher, A.; Hanlon, A. M.; Tuten, B. T.; Tooley, C. A.; Frank, P. G.; Berda, E. B. Polym. Chem. 2015, 6, 181-197.

(48) Arruebo, M; Fernandez-Pacheco, R.; Ibarra, M. R.; Santamaria, J. Nano Today 2007, 2, 22-32.

(49) Wohlfart, S; Gelperina, S.; Kreuter, J. J. Control Release 2012, 161, 264-273.

(50) Mecerreyes, D.; Humes, J.; Miller, R. D.; Hedrick, J. L.; Detrembleur, C.; Lecomte, P.; Jerome, R.; San Roman, J. Macromol. Rapid Commun. 2000, 21, 779-784. 
The factors affecting the formation of single-chain polymeric nanoparticles (SCNP) at high polymer concentration $(\sim 100$ $\mathrm{mg} \cdot \mathrm{mL}^{-1}$ ) via organo-catalyzed ring-opening polymerization is investigated in this study. Specifically, the role of ethylene glycol brushes in the linear polymer precursor, and the effect of alcohol initiator structure and concentration are determined. The fundamental knowledge derived from this study may lead to the development of new SCNP for future targeted applications.

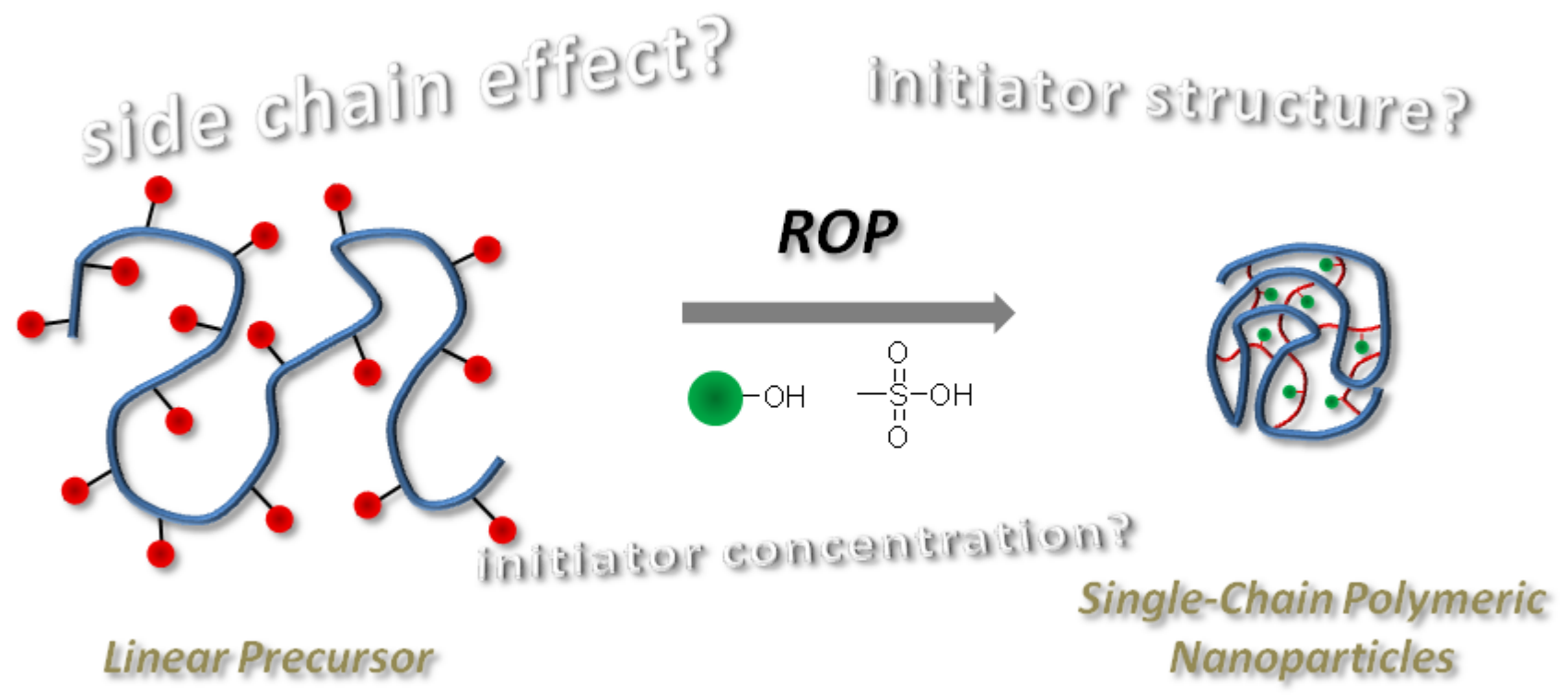




\section{University Library}

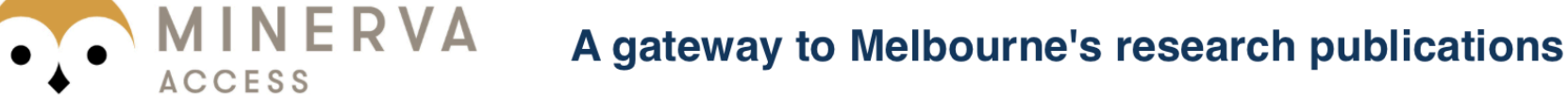

Minerva Access is the Institutional Repository of The University of Melbourne

Author/s:

Wong, EHH;Qiao, GG

Title:

Factors Influencing the Formation of Single-Chain Polymeric Nanoparticles Prepared via Ring-Opening Polymerization

Date:

2015-03-10

Citation:

Wong, E. H. H. \& Qiao, G. G. (2015). Factors Influencing the Formation of Single-Chain Polymeric Nanoparticles Prepared via Ring-Opening Polymerization. MACROMOLECULES, 48 (5), pp.1371-1379. https://doi.org/10.1021/ma502526c.

Persistent Link:

http://hdl.handle.net/11343/54841 